\title{
8.3 Основные необходимые факторы эффективного развития строительной организации и проблемы внедрения инноваций
}

Целью деятельности любого предприятия является получение ценного продукта или услуги и как результат для получения прибыли не только для телеономического выживания, но и для развития. Прибыль очень важный pecyрс. Для этого используется экономический потенциал предприятия и реализуется соответствующий стратегический план. Для достижения поставленных целей предприятия работают над созданием конкурентоспособного продукта, качество и цена которого соответствуют требованиям потребителей, в то же время с низкими затратами и короткими сроками производства. Вопросы качества становятся все более актуальными с каждым годом. В то же время организационные структуры предприятийпроизводителей и подходы к организации производства имеют свои различия, поскольку существуют разные социальные системы, методы производства и производственные отношения. Таким образом, для отдельного предприятия, как первичной ячейки организма любой экономической системы, необходимо абстрагироваться от состояния макро- и мезо-таргетинга и учитывать информацию о факторах внутренней среды, основные компоненты которых это маркетинг, производство, финансы, персонал, исследования и разработки. Формирование внутренней среды организации-синергического взаимодействия формальной и неформальной оргструктуры, создание генома деловой и духовной культуры имеют огромное значение для развития и уровня функционирования любой социальной системы, однако не менее важным, если не решающим является фактор рационального управления и создание благоприятных условий для производственных и социальных отношений в обществе государственными институтами. Таким образом прогресс в развитии любой организации ,в том числе и строительной, определяется не только внутренними и внешними условиями, но и используемыми средствами и методами управления. 
В сегодняшнем 21-ом веке с бурно развивающейся техникой и технологиями кажется , что неразрешимых проблем нет и все задачи решаются легко и просто.Так кажется, пока не приходит осознание того , что погоня за комфортом и техническими благами подогнала человечество к краю пропасти и на первом плане не чудеса науки и техники, а морально-этические принципы поведения в мировом сообществе людей и общения с Природой. Всесилие людей ,ослепленных жаждой наживы ,поворачивается бедой для всего человечества.

Наличие такого факта или явления, как непредвиденные обстоятельства, накладывает ограничения на выбор альтернатив и возможность точного прогнозирования и планирования. Это следует из относительных, но неоспоримых ограничений знаний об организационных структурах и организационных процессах, нет абсолютных знаний о чем-либо из-за изменчивости природы и мира. Цель и результат никогда не совпадают точно. [499] Все происходит в соответствии с законами теории вероятности, теории информации, теории хаоса, теории катастроф и наконец в соответствии с Вселенскими законами, которых человечеству не все дано и знать.

Естественно желание узнать больше и достичь наивысшего уровня совершенства, но познание и развитие не имеют границ, этот процесс бесконечен. Поэтому изоморфизм структуры строительной организации является естественным явлением, которое было теоретически обосновано в работе В.И. Савенко и С.И. Доценко. [500] Показано, что модель сбалансированной системы показателей является вполне теоретически объяснимо . по своей структуре на основе бинарных отношений в форме диалектического единства категории «общее» и «единичное» ,причинноследственных связей и является практическим примером модели знаний о предметной области на основе центральных законов интегративной деятельности мозга $[501,511]$. Принцип диалектических отношений категории в форме «общее» - «единочное» используется в исследованиях такого типа 
отношений и их роли в исследуемых моделях. Энергия, освобождающаяся при разрешении антиномий , является движущей силой развития системы.

В этом случае определяющими внутренними факторами являются: 1) персонал (владельцы, менеджеры и исполнители), 2) инфраструктура, машины, механизмы и инструменты, 3) ресурсы (финансовые, материальные, энергетические, интеллектуальные и другие), 4) используемые методы, технологии, инновации (Рис.1) [502] Внешние факторы- международные отношения, финансовые рынки, макроэкономика в мире, местное самоуправление, население, местные региональные рынки, ближайшая среда, конкуренты и партнеры. потребители, климат и погода, демография, отраслевые рынки, состояние, макроэкономика в государстве, духовная и деловая культура , Вселенские законы. Все эти факторы, как внутренние, так и внешние, безусловно, влияют и определяют развитие любой организации в том числе и строительной или сельскохозяйственной, действующей под открытым небом и в огромной мере зависящей от милости Природы. (Рис.1). [502] 


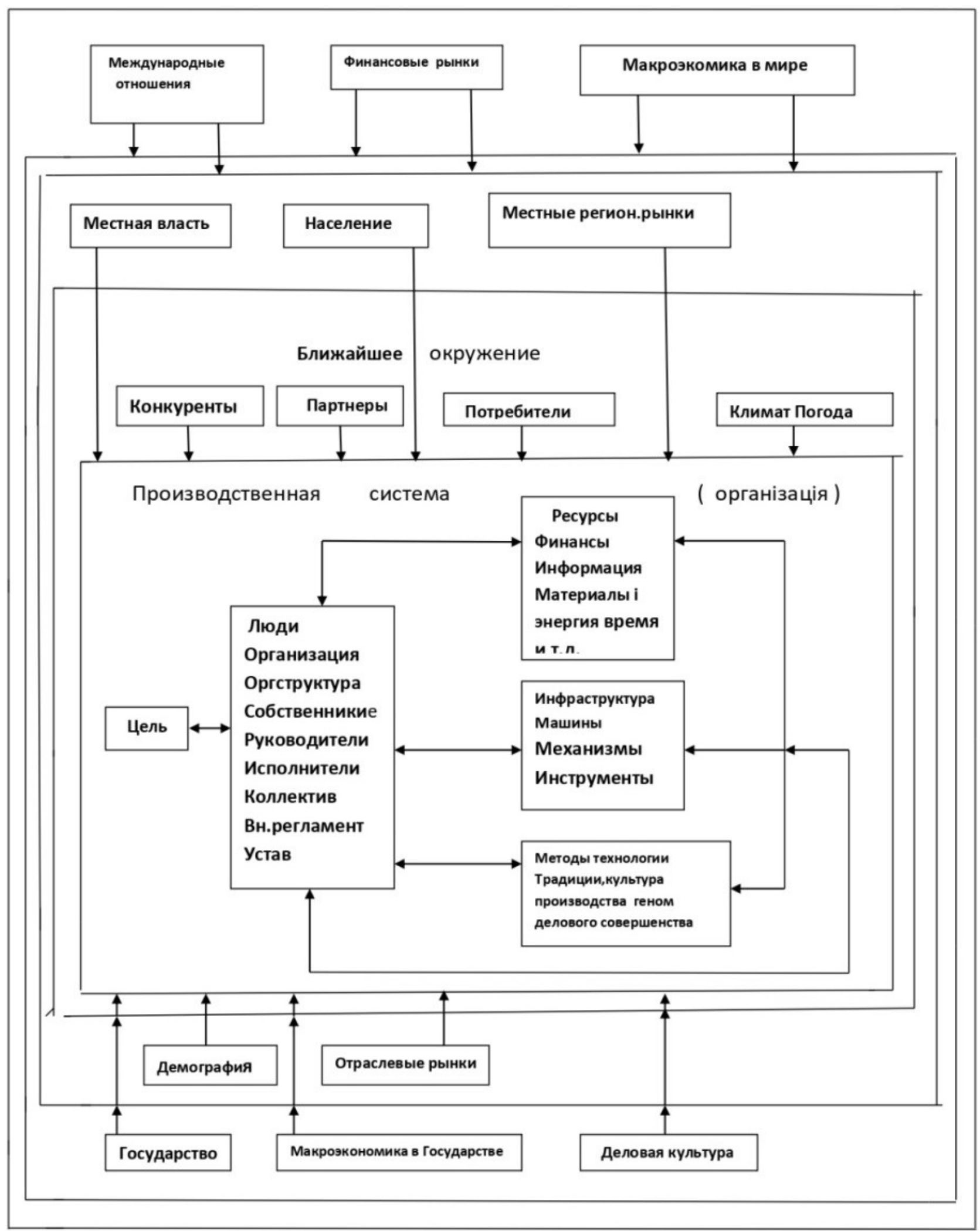

Рис. 1. Внутренняя и внешняя среда организации, связи и взаимодействия 
Организация, возглавляемая лидерами (собственники, менеджеры, исполнители), создающими геном(традицию) высокой духовной и деловой культуры, которые организуют синергетическое взаимодействие управляющей и управляемой подсистемы, формальной и неформальной организационных структур организации при обязательной поддержке государства, должным образом оценивают и своевременно учитывают внутренние и внешние факторы ,обречены на успех. [503,509]

На современном этапе, исходя из опыта прошлых лет, успех может быть достигнут только при государственной поддержке в виде создания благоприятных условий для деятельности организаций.

Первым шагом к достижению телеономного уровня выживания является приведение деятельности организации в соответствие с международными стандартами серии ISO 9001-2000 (2015), что соответствует уровню 250-300 баллов по 1000-балльной шкале EFQM. Второй шаг - внедрение модели совершенства TQM или EFQM. Это позволяет достичь уровня 450-500 баллов по шкале EFQM, а может и больше, но это при серьезной научной и инновационной поддержке. Без науки и инноваций лидером стать невозможно. Внедрение даже самых передовых моделей - это следование за лидером. Совершенно новые пути развития - это пути научных открытий и изобретений.[504,505] Будущее лидирующее положение любой компании, также и строительной, определяется способностью лидеров и всего персонала осваивать наукоемкие инновационные технологии, генерировать и быстро внедрять свои изобретения и открытия. Будущее за наукой и учеными-изобретателями высоко интеллектуальными и духовными людьми , для которых открыта всеобщая информационная система и всеобщие Вселенские законы. Такими были Будда, Иисус Христос, Перикл, Сократ, Пифагор, Платон, Никола Тесла, а также наши великие соотечественники А.А.Богданов, В.М. Глушков , А.Д. Сахаров, идеи которых стали историей так и не реализовавшись из-за непонимания впасть имущих и 
общества в целом. Поэтому трудно переоценить роль в прогрессе организаций и общества в целом управляющих государственных институтов.

В системе управления реализуется процесс взаимодействия объекта управления и управляющей системы. Управляемость системы одно из основных свойств, характеризующих состояние системы и ее организованность.

Вырабатываемые управляющей системой команды (управляющие воздействия) всегда направлены на уменьшение разнообразия, т.е. числа возможных состояний управляемого объекта - системы. Идеальный вариант характеризуется сведением всех возможных состояний к одному, заранее намеченному. Для того, чтобы управляющая система могла эффективно справляться с этой задачей, она, как показал У.Р. Эшби, должна сама обладать необходимым разнообразием, так как «только разнообразие может уничтожить разнообразие» [505] Наиболее совершенной формой саморегулирования с использованием обратной связи является самоорганизация (гомеостазис). Обеспечивается так называемая сверхстабильность, т.е. способность системы возвращаться к состоянию равновесия после воздействия различных случайных возмущений.[506] Следует отметить широкое распространение самоорганизации в живой природе. Отдельные важные ее черты присущи также техническим и экономическим системам. Самоорганизующая система в принципе является многоконтурной. В ее основе лежит некоторая исходная управляющая система, которая обменивается информацией с объектом управления (первый контур). В результате такого обмена и обеспечения необходимой реакции на «нормальные» внешние воздействия достигается равновесное состояние системы.

Помимо первого контура, в самоорганизующейся системе должен функционировать по крайней мере еще один контур (второго порядка). Это необходимо,чтобы встроенная в него система управления контролировала и прогнозировала эффект, вызываемый деятельностью первого контура. В том случае, если результаты контроля и прогноза оцениваются системой второго уровня как неудовлетворительные (при отличных от «нормальных» внешних 
воздействиях),она вносит изменения в правила функционирования первой системы. В принципе, самоорганизующая система обычно имеет больше двух уровней управления [507] В экономических системах переходу к эффективным формам саморегулирования и самоорганизации существенно способствует согласованность производственных целей разных уровней управления и обеспечение эффективного взаимодействия людей, имеющих подчас различные интересы, в направлении достижения этих целей.

В строительной системе информация по каналам прямой связи передается в виде команд (управляющих воздействий) руководства, по каналам обратной связи - в виде сведений о постоянно меняющейся обстановке на стройке. Кроме того, поступают сведения о возмущающих воздействиях извне. Информация может не только передаваться по каналам связи, но и хранится в записанном виде (в книгах, на чертежах, в «памяти» электронной вычислительной машины, в клетках головного мозга человека и т.д)

Известно много определений понятия «информация». Ее характеризуют как обозначение содержания, полученного из внешнего мира коммуникацию, связь, в процессе которой устраняется неопределенность ,ограничение разнообразия и т.п. Наиболее важно при определении информации то, что обычно заранее невозможно предугадать, какое именно произойдет событие из числа многих возможных, т.е. информация всегда связана с элементом-неопределенности, случайности. Таким образом, с наиболее общей точки зрения процесс получения информации есть процесс снятия неопределенности в результате того, что из некоторой совокупности возможных в данной конкретной ситуации явлений выделяется явление, фактически имевшее место». Основная задача автоматизированной системы управления, сформулированная В.М. Глушковым, состоит в том, чтобы обеспечить оптимальное функционирование объекта управления (производственной организации, объединения, отрасли и т.п.) как единого целого, за счет правильного выбора целей и путей их достижения, 
наилучшего распределения заданий между отдельными частями, из которых состоит объект, и обеспечения их четкого взаимодействия.[508]

Сегодня как никогда актуальны работы незаслуженно подзабытого А.А.Богданова с его Всеобщей организационной наукой-тектологией [509],идущей вразрез с тупым, некогда господствовавшим атеизмом. Действующая ныне теория развития организаций Пригожина А.И.[510] должна бы стать настольной книгой каждого предпринимателя и преподавателя этого профиля, но нет пророка в своем Отечестве. С открытым ртом слушаем, что изрекут и напечатают нам на английском языке. Своих заметить трудно-они же рядом.

История отношений науки, как отдельных ученых так и общественных научных организаций, с официальными государственными научными институтами всегда носила сложный, а порой и драматический характер. Так было, так остается в настоящее время, к сожалению.[513,с.272 ] Стоит только вспомнить имена великих подвижников науки и выдающихся ученых разных времен и народов Пифагор, Сократ, Платон, Авиценна, Апполоний Тианский, Николай Коперник, Филиппо (Джордано) Бруно, Галилео Галилей, Исаак Ньютон, Михайло Ломоносов, Нильс Бор, Томазо Кампанела, Макс Планк, Дмитрий Менделеев, Альберт Энштейн, Никола Тесла, Александр Богданов, Андрей Сахаров, Вернадский В.И., Козырев Н.А., Глушков В.М. Левашов Н.В. Гаряев П.П. и еще тысячи гениев, которых всех и перечислить непросто.. Стоит вспомнить ныне действующих, сегодняшних, борющихся за признание, за право быть услышанными Леонова В.С., Сухоноса С.И., Валерия Кондратова, Гриняева А.ф. , Деревенского O.X. и многих других. И у каждого из них на пути познания и развития стояли серьезные, а порой опасные препятствия официальных институтов, инквизиции от религии и инквизиции от науки, различного рода комитетов по борьбе со лженауками.

По вине государственных деятелей, политиков и администраторов науки, руководителей академий, преследовались и тормозились научные разработки, 
целые направления в науке: генетика, кибернетика, не признавались, всячески тормозились и засекречивались такие науки как тектология (А.А.Богданова, опередившего на 3-и десятилетия своих современников), развитие кибернетических сетей управления экономикой всей страны (Глушков В.M. лишенный возможности внедрить свои передовые разработки в жизнь партийным руководством и академией наук СССР). Идеи академика Сахарова А.Д, всемирно известного физика-ядерщика, по организации и структуре отношений между советскими республиками и в обществе не были услышаны, остались не понятыми тогдашним руководством страны и осуждались высшим руководством Академии наук СССР, как непрофессиональные. Козырев Н.А. прошел тяжелейшие и несправедливые испытания и все же защитив свои идеи в докторской диссертации и последующих научных открытиях о сущности времени, как физического явления, но так и не получил должной заслуженной оценки, соционика (учение о типах информационного метаболизма-Аушра Аугустинавичюте ), саентология и дианетика (учение о деятельности человеческого разума-саентологическая церковь и международная ассоциация саентологии, основанные Р.Л. Хаббардом ).

Таких примеров множество. Они свидетельствуют о том, что много основополагающих теорий и целых направлений в науке и технике, гуманитарных науках,тормозятся из-за некомпетентности или сознательного субъективного противодействия развитию научных теорий государственных научных институтов и отдельных высокопоставленных чиновников от науки. Кроме политических факторов видимо работает еще и принцип, эффект Лоуренса Питера. Так было, время прошло, а все повторяется. Бьются безрезультатно о стену равнодушия со своей теорией гравитации и антигравитации Гриняев А.Ф. и Деревенский О.Х.. Выступает на разных симпозиумах и выставках ученый Леонов В.С, да только опубликовать его книгу «Новая Физика» взялись Англия и Индия на английском языке, а в родном Отечестве в упор не хотят замечать и по достоинству оценить. А ведь найдены решения глобальных энергетических и экологических проблем. Не замечают и нашего Ващенко В.Н, открывшего людям глаза на ошибки создателей теории глобального потепления, изменения озонового слоя Земли, и сегодня 
активно трудящегося без необходимой поддержки и понимания, создавая уникальный прибор для утилизации всех видов отходов и мусора на основе плазменно-химического реактора.

Несколько лет безуспешно тянется вопрос внедрения и эффективного использования уникальной технологии по защите от коррозии и повышения устойчивости и сроков службы металлических конструкций и изделий с помощью экологически чистого материала на растительной основе CONTRRUST ( Автор патента Высоцкая Л.Н. и авторский коллектив разработчиков научно-технических материалов и публикаций ,a также документов для участия в различных инновационных конкурсах и программах: Каратеев А.М.,Плугин А.А.,Савенко В.И.,Кущенко И.В. Ващенко В.Н., Машков О.А., Максимов С.Ю., Журавский А.Д. и другие ).[503] Научные и государственные институты при этом практически были безучастными, кроме похвальных грамот и сертификатов, поддержки никакой. Как говорится , надо ж дать. А сколько неизвестно. Сегодня , когда некомпетентными политиками принимаются абсурдные решения и раздувается психоз с политической выгодой и не ищутся причины, а ведутся неуклюжие попытки борьбы со следствиями , мудрый доктор из Львова Анатолий Незгода успешно борется со всеми видами пневмонии, включая коронавирусную, запантовал свой метод лечения всех видов пневмонии (включая и коронавирусную), ВИЧ и даже рака, но его не слышат и в упор не видят те кому положено видеть такие спасительные вещи в первую очередь. Более того даже мешают внедрению в практику. Видимо преследуются другие неблаговидные цели.

Важнейший вопрос выживания человечества, в сложившейся в настоящее время экологической ситуации, выходит на первое место, но снова, даже перед лицом реальной глобальной угрозы, власть имущие, государственные и научные институты не видят и не слышат выдающихся современных-ученых, не облеченных властью над людьми, но имеющие разум и талант.

Проведенный анализ публикаций инновационных научных работ ученых, не имеющих поддержки властных структур и лишенных возможности представить на 
суд широкой научной общественности результаты своих исследований и научных теорий и открытий, а также натурные, лабораторные исследования и собственный опыт разработок и внедрения инновационных работ авторов позволяет утверждать, что рассмотрение и оценка научно-технических трудов официальными научными институтами проходит недостаточно прозрачно и объективно. Еще более сложный путь от рассмотрения до внедрения. Так работа авторов на соискание Государственной премии Украины в области науки и техники «Энергоэффективные технологии ускоренного возведения объектов жилищного и гражданского строительства» удостоена премии в 2013 году с шестого раза, а ведь терпение авторского коллектива могло иссякнуть и после третьего раза. Результаты практически были те же, разве что объемы внедрения наращивались да состав конкурентов изменялся.

Работа на соискание Государственной премии Кабинета министров по инновационным технологиям в области экологически чистой защиты от коррозии металлических конструкций и изделий веществом на растительной основе CONTRRUST пять раз безуспешно подавалась в конкурсную комиссию. А в ответ равнодушное молчание. Дело же ведь не в медалях и премиях, а в том, чтобы компетентно оценили и применяли разработку. Применяют единицы, кто уже попробовал, в Беларуси, Казахстане, Грузии, Азербайджанеи т.д, но не на Родине. Очень интересуются китайцы, но не столько продуктом, сколько технологией изготовления и применения. А что же официальные научные институты и авторитеты? Кроме серии дорогостоящих испытаний, положительных заключений и сертификатов,- ничего. Аналогичную ситуацию наблюдаем и в исследованиях Леонова В.С. (до сих пор не может опубликовать фундаментальный учебник «Новая физика» и внедрить в полной мере поистине революционные идеи в энергетике,космонавтике,ядерной физике и т.д.), Гриняев А.Ф и Деревенский О.Х. безрезультатно бьются о стену равнодушия со своей теорией о природе гравитации и антигравитации, также как и Валерий Кондратов с его Тканью Мироздания , которая может сравниться со всемирно известной таблицей периодических элементов Менделеева. Ващенко В.Н.,известный антарктический исследователь 
изобличивший несостоятельность теории озоновых дыр, не имея должной, поддержки, пытается развернуть борьбу с вредными отходами и мусором с помощью своего уникального прибора на основе плазменно-химического высокотемпературного реактора. А поддержки нет, скорее наоборот. Случай с уникальной фундаментальной теорией научной школы Плугиных особый и нуждается в более подробном рассмотрении и обсуждении, поскольку это дело всей жизни Плугина А.Н.,касается жизни всего Человечества.А мыслимых и немыслимых , лабораторных ,натурных, аналитических и практических опытов и исследований было проведено более, чем достаточно не на одну жизнь.

В виду особой важности для Человечества фундаментальной научной теории школы Плугиных из Харькова жизненно необходимо обратить на нее внимание широкой научной общественности и компетентных руководителей самого высокого уровня всех стран. Пусть даже это повлечет за собой самые строгие дискуссии, проверки и испытания. Это ведь нужно в интересах всех людей на Земле. И самое главное, что время не терпит, его уже нет.. Школа профессора Плугина А.Н. как раз принадлежит к числу ученых, которые осознавая опасность, созданную людьми по недопониманию, критическую для всей Земли, для всей цивилизации, ситуацию, силой своего разума и таланта постигли причины беды, предлагают выход и должны быть услышаны.

Гипотеза о влиянии электрических явлений на геологические процессы и глобальные события изложены и аргументирована вескими доказательствами в в многочисленных, в том числе в рецензированных наукометрических базах, трудах.[515]

Глобальное потепление официально признано одним из аспектов изменения климата Земли, и основным его фактором является резкое антропогенное увеличение концентрации парниковых газов, особенно двуокиси углерода (CO2). Однако многие ученые не согласны с этой точкой зрения и не считают антропогенный фактор основной причиной. Таким образом, рассматривая меры по ограничению выбросов парниковых газов как бесполезные. Авторы новой теории 
(научная школа Плугиных) считают, что настоящая причина - отсутствие однозначных идей в рамках Науки о планете Земля. Целью исследования, представленного в статье [515,516], является установление истинных причин глобальных катастроф, глобального потепления, их стремительного роста в последнее время, особенно в последние десятилетия и степень их опасности, а также выявить их характер и актуальные механизмы. Авторы новой теории критически проанализировали и сопоставили имеющиеся данные по мировым процессам и катастрофам на Земле с древнейших времен до наших дней выявили их актуальные механизмы на основе субмикро- и макроколлоидной химии и физико-химической механики Земли - новой науки о Земле, созданной авторами. Авторы показали, что движущая сила всех глобальных явлений и процессов на Земле - это электрическая сила, обусловленная избыточным отрицательным электрическим зарядом Земли, а причина приближающейся глобальной катастрофы - ненормальный рост заряда за последние десятилетия. Статья посвящена критическому анализу экспериментальные данные о динамике глобальных катастроф, в том числе изменение температуры Земли и уровня океана, большое количество углекислого газа и атмосферная пыль. ( Авторы Плугин А.Н.,Плугин А.А. и другие члены школы, опубликовано EDP Sciences, 2020, Материал статьи № 02001 был представлен на Международной онлайн конференции по устойчивому будущему: экологические, технологические, социальные и экономические вопросы (ICSF 2020), 22 апреля 2020г.). А реакции надлежащей нет. Не слышит не только научное сообщество, но и те , кому положено такие серьезные сигналы слышать и предпринимать адекватные меры.

С надеждой на то, что несмотря на замалчивание и сокрытие выдающихся научных разработок и открытий, дабы не выглядеть такими какими они есть, явно не государственные чиновники не смогут воспрепятствовать прогрессу науки. А прогрессивная научная общественность поддержит и поможет выйти в свет, опубликовать у себя на родине, в Украине, уникальный научный труд доктора химических наук, профессора, лауреата Госпремии Украины в области науки и техники, Плугина А.Н.,Плугина А.А. и всех членов его школы. На основе 
принципиально новой научной теории об избыточном отрицательном заряде Земли (ИОЗ) рассмотрены причины, механизм и реальные пути остановки пандемии коронавируса COVID.-Установлено, что главная причина пандемии - чрезвычайно высокое количество и масса запускаемых космических ракет с конца прошлого века, что привело к накоплению огромного ИОЗ Земли, выше предельного для начала пандемии. Непосредственной причиной явились запуски в очень большом количестве ракет Китаем в ноябре-декабре 2020 года. Даны предложения: в первую очередь остановить указанные запуски всеми странами или установить мораторий на определенное время.

О научном направлении: Научной школой доктора химических наук, профессора Плугина А.Н. в последние годы впервые в истории науки доказана применимость положений фундаментальной материаловедческой дисциплины «Физико-химическая механика дисперсных систем и материалов», научной основы школы, к глобальным и субмикроскопическим процессам во Вселенной, Галактике и на Земле.[516] Раскрыта природа возникновения этих процессов на основе реальных (а не фантастических) исходных всепроникающих элементарных частицреонов, и ареонов, обладающих зарядом электрона и позитрона,но массой меньшей в 10 млн.раз. Реоны испускаются (эмитируются) свободными или слабо связанными электронами. Основным источником этих электронов и создаваемого ими электрического поля на поверхности Земли является термодиффузия электронов из раскаленного $(6000$ C) ядра Земли к ее холодной поверхности (в среднем 140 С). Средняя напряженность такого электрополя равна - 130 В/м (равновесная величина). Движущей силой абсолютно всех процессов во Вселенной и на Земле является напряженность электрополя, умноженного на заряд. Не очень большие отклонения от равновесной напряженности обусловили возникновение и развитие жизни на Земле. Очень большие отклонения приводили к Глобальным катаклизмам, гибели цивилизаций. Глобальное потепление, многократный рост количества и частоты сильнейших землетрясений, вулканов, ураганов, наводнений, лесных пожаров, авиакатастроф и др., в последние десятилетия, смертоносные новые вирусные заболевания ВИЧ/СПИД, коронавирус и восстановление старых 
массовых заболеваний, в последнее время происходят из-за накопления в огромном количестве ИОЗ, источником которого являются запуски космических ракет (более 5 тыс.шт.), особенно супертяжелых «Спейс шаттл» (американский многоразовый транспортный космический корабль) в последние несколько десятилетий, никогда ранее не запускавшихся. ИОЗ порождается почти мгновенным сгоранием огромного количества ракетного топлива с разделением его на положительный заряд (остатки от згорания, остающиеся в зоне запусков) и отрицательный (раскаленная масса, содержащая электроны), который с огромной скоростью уносится в атмосферу и космос.[515.516] Реально приблизилась опасность гибели современной цивилизации при дальнейших неумеренных запусках ракет, планируемого освоения Луны и Марса. Предложены реальные меры предотвращения этого, одной из основных является немедленная остановка неумеренных запусков тяжелых и супертяжелых космических ракет или мораторий на определенное время, а также популяризация указанного научного направления, развертывание научных исследований, обновления учебного процесса и др.[517] Новые научные основы дают возможность прекратить массовое уничтожение ископаемых энергоресурсов, создание новых альтернативных и возобновляемых источников энергии и транспортных средств, что позволит остановить приближающуюся гибель цивилизации. Такие меры позволят сэкономить многомиллиардные затраты на запуски космических ракет, на устранение последствий катастроф и борьбу с пандемиями. Следует отметить, что новая теория, предлагаемая Плугиным А.Н. противоречит т.н. фундаментальным положениям, которые, на наш взгляд, сегодня явились тормозом развития Реальной науки о Земле.[518] Основные положения указанного направления изложены в нескольких томах бесплатного издания Ламберт пресс (в Германии) на руссом языке. Но их там никто не читает. Была попытка представить статью в журнал «Физика Земли», но отвергнута из-за несоответствия фундаментальным положениям, так называемой официальной науки. Необходима широкая публикация указанных материалов, однако достаточных средств и негласный 
запрет публикаций в российских изданиях не позволяют это осуществить собственными силами.Необходима поддержка.

Выводы

1 Рациональное потребление и расходование всех видов ресурсов , организация и управление процессами возможно лишь при условии четкого и максимально точного учета факторов внутренней и внешней среды организации

2. Исходные данные для проектирования и организации производственных процессов должны максимально соответствовать реальным условиям.

3. Управление должно быть гибким и устойчивым даже в условиях возможных неопределенностей. Для этого должны максимально использоваться современные компютерные средства и информационные технологии во главе с высокоинтеллектуальным и компетентным человеком-руководителем

4. Государство и общество должно всячески поддерживать и поощрять развитие науки и личности высокоморальных ученых и изобретателей, так как именно они определяют уровень развития научно-технического прогресса, уровень производительных сил и производственных отношений общества.

5. Создание генома высокой деловой и духовной культуры,создание благоприятных условий и среды в организации и обществе зависит и определяется государственными институтами , интеллектуальной и духовной зрелостью общества в стране и по большому счету решает судьбу всей экономической формации. 